\title{
発達した後下小脳動脈に発生した解離性動脈瘤 一症例報告一
}

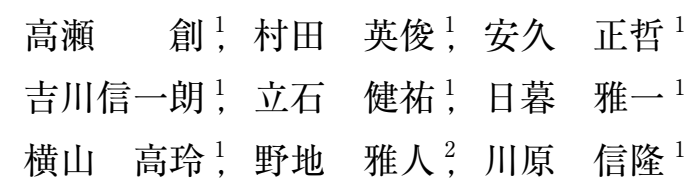

\section{Dissecting Aneurysm of Well-developed Posterior Inferior Cerebellar Artery: A Case Report}

\author{
Hajime Takase, M.D., ${ }^{1}$ Hidetoshi Murata, M.D., ${ }^{1}$ Masaaki Agu, M.D. ${ }^{1}$ \\ Shin-ichiro Yoshikawa, M.D., ${ }^{1}$ Kensuke Tateishi, M.D., ${ }^{1}$ Masakazu Higurashi, M.D., ${ }^{1}$ \\ Taka-akira Yokoyama, M.D., ${ }^{1}$ Masato NoJ, M.D., ${ }^{2}$ and Nobutaka KawahARA, M.D. ${ }^{1}$ \\ ${ }^{1}$ Department of Neurosurgery, Yokohama City University Graduate School of Medicine, \\ Yokohama, Kanagawa, and ${ }^{2}$ Department of Neurosurgery, Kanagawa Prefectural Ashigarakami \\ Hospital, Kanagawa, Japan
}

Summary: We report a rare case of dissecting aneurysm of the posterior inferior cerebellar artery (PICA) with vascular variation. A 38-year-old man, who had no medical, familial or traumatic histories, presented with headache, nausea and mild consciousness disturbance. Computed tomography (CT) imaging demonstrated subarachnoid hemorrhage with intraventricular hemorrhage. Angiography disclosed an aneurysm of left PICA, which did not involve the vertebral artery. The PICA was well developed and widely perfused the cerebellum and lower brain stem, which was accompanied by lack of ipsi-lateral anterior inferior cerebellar artery (AICA) and contra-lateral PICA. The aneurysm was successfully treated by trapping and revascularization procedure with occipital artery (OA)-PICA anastomosis.

We suggest that congenital vascular variation related to well-developed PICA might lead to dissecting aneurysm, and that direct surgical treatment with bypass would be indicated for such patients to preserve hemodynamic integrity.

\author{
Key words: \\ $\cdot$ posterior inferior \\ cerebellar artery \\ - subarachnoid hemorrhage \\ - dissecting aneurysm \\ - OA-PICA anastomosis \\ - vascular variation
}

Surg Cereb Stroke

(Jpn) 42: 136-141, 2014

\section{はじめに}

後下小脳動脈 (posterior inferior cerebellar artery; PICA) に発生する動脈瘤の多くは椎骨動脈分岐部に生じ,
その発生頻度は頭蓋内動脈瘤の 0.49-3.0\% とされている一 方で, PICA に限局して発生するものは 0.28-1.4\% と報告 されている ${ }^{14)}$ ，その多くは囊状動脈瘤であり, 解離性瘤は そのうち $6.7-41 \%$ とまれであり, いずれも症例報告に留ま

\footnotetext{
${ }^{1}$ 横浜市立大学大学院医学研究科 脳神経外科学, ${ }^{2}$ 神奈川県立足柄上病院 脳神経外科(受稿日 2013.6.29) (脱稿日 2013.11.5)〔連絡先： 干236-0004 神奈川県横浜市金沢区福浦 3-9 横浜市立大学大学院医学研究科 脳神経外科学 高瀬 創] [Address correspondence: Hajime TAKASE, M.D., Department of Neurosurgery, Yokohama City University Graduate School of Medicine, 3-9 Fukuura, Kanazawa-ku, Yokohama, Kanagawa 236-0004, Japan]
} 


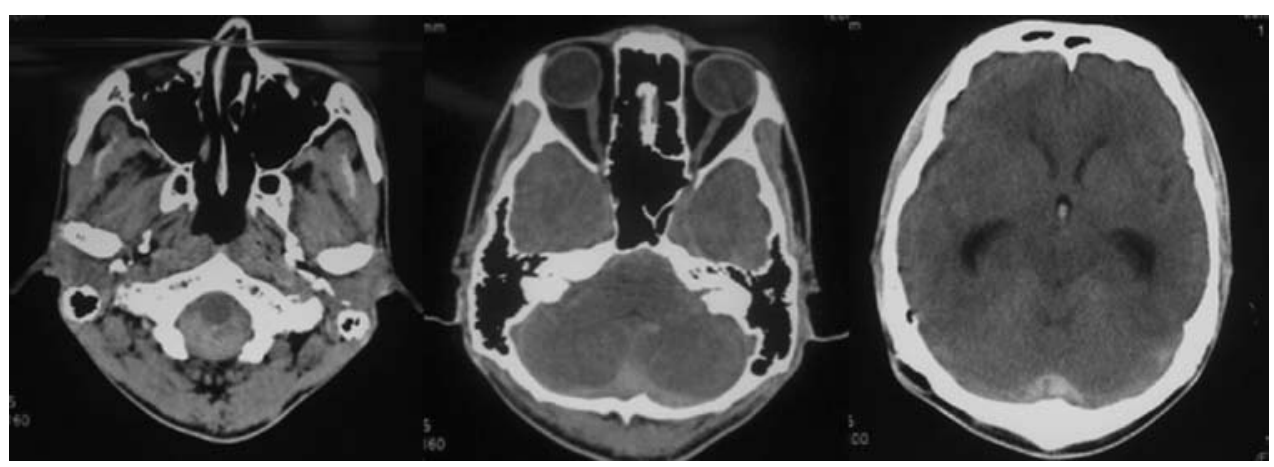

Fig. 1 Head CT scan on presentation showing diffuse SAH with intra-ventricular hemorrhage. SAH was especially thick in posterior fossa.

るがゆえ，発生原因や治療方針は症例ごとに検討されてい るのが実情である ${ }^{16(26) 35) 37) . ~}$

今回われわれは, 特徵的な血管の破格に合併した非分岐 部後下小脳動脈解離性動脈瘤症例を経験したため, 同動脈 瘤の形態学的特徵を詳述し, 発生原因と治療選択に関し文 献的考察を加えて報告する.

症例

患者 : 38 歳, 男性.

主訴：後頭部痛, 嘔気, 意識障害.

既往歴：内科疾患なし, 外傷なし.

家族歴：特記事項なし.

現病歴：前日に自覚した突然の後頭部痛・嘔吐・軽度の 意識障害を主訴に, 前医を救急受診した. 初診時意識レべ ルはJapan Coma Scale (JCS) 2, 項部硬直, 脳神経症状 なく, 四肢の運動知覚も左右差はなかった. 頭部単純 CT 上, 後頭蓋窩優位のびまん性のくも膜下出血 (subarachnoid hemorrhage; SAH) と, 少量の第四脳室内出血を認 めた(Fig. 1). SAH (WFNS grade 2, Fisher group 4) の診断のうえ, 同日(第 1 病日) 入院となった。第 2 病日, 脳血管撮影にて以下の所見の動脈瘤を認め, 第 6 病日に加 療目的に当院転送となった.

当院入院時所見：Japan Coma Scale (JCS) 2, Glasgow Coma Scale (GCS) 14 (E4V4M6), 血圧 140/92 mmHg, 軽度の意識障害以外の明らかな神経学的脱落症状を伴わ ず，前医初診時と大きな変化はなかった。

脳血管撮影所見 : 左椎骨動脈造影 (vertebral arteriography; VAG)にて左 PICA の近位部に紡錘状の拡張を認め, 解離性動脈瘤からの出血と判断した(Fig. 2). 左 PICA は 大きく発達拡張しており, 後頭蓋窩尾側の大部分を灌流し ていた。一方で左 AICA と右 PICA は画像上描出されず, また右 AICA は低形成であった。なお，主幹動脈に明ら かな血管攣縮所見は認めなかった。
入院後経過 : 第 9 病日, 2 回目の脳血管撮影を行い, 主 幹動脈に攣縮所見のないこと, 解離腔の拡大がないことを 再度確認した。 その際, 紡錘状動脈瘤上に新たに囊状隆起 所見を認め, 仮性瘤が増大し破裂が切迫していると判断し た(Fig. 3)。第 11 病日に脳動脈瘤 trapping, 後頭動脈一後 下小脳動脈吻合術(OA-PICA anastomosis)を施行した. 術中所見では, 動脈痕は紡錘状の変化を伴っており, 解離 性動脈瘤が強く示唆された。動脈瘤は穿通枝を含んでおら ず, 動脈瘤のトラッピングと遮断遠位部での後頭動脈-後 下小脳動脈吻合を施行した(Fig. 4). 動脈㢚近傍に穿通枝 が存在したため動脈壁の切除は断念し, 血腫部分のみ摘出 したが, 動脈壁成分はみられなかった. 術後経過は良好で あり, 第38病日に神経脱落症状なく独歩退院となった (Fig. 5). 術後 3 年経過した現在も後頭動脈一後下小脳動脈吻合 の開存は良好であり, 再出血や虚血症状は認めず経過良好 である.

\section{考察}

PICA に限局した動脈瘤は, 画像技術の進歩に伴ってそ の診断精度が向上し, 発生率は全脳動脈瘤の $0.28-1.4 \%$ と 報告されているが，そのほとんどは囊状動脈瘤であり，解 離性のものは比較的まれと考えられている ${ }^{1422935)}$. 頭蓋内 解離性動脈瘤の発生に関しては, これまで梅毒などの感染 関連のもの以外には, 結節性多発動脈炎, 線維筋性異形成 などの全身疾患や外傷に関連するものが報告されている. しかし，PICA に限局する解離性動脈瘤は少数報告が散見 されるのみであり, 大血管解離への関与が示唆されている 巨細胞性動脈炎に合併した症例や, 外傷 (手術) 後に発生し たもの，原因として segmental mediolytic arteriopathy が疑われる例などが報告されているが，発生原因はいまだ 同定されていない(1)3437). 後頭蓋窩の血管系はその variation が豊富であるとされ, 各種空形成や共通幹 (AICAPICA), PICA end, PICA extradural origin, 血管低形 


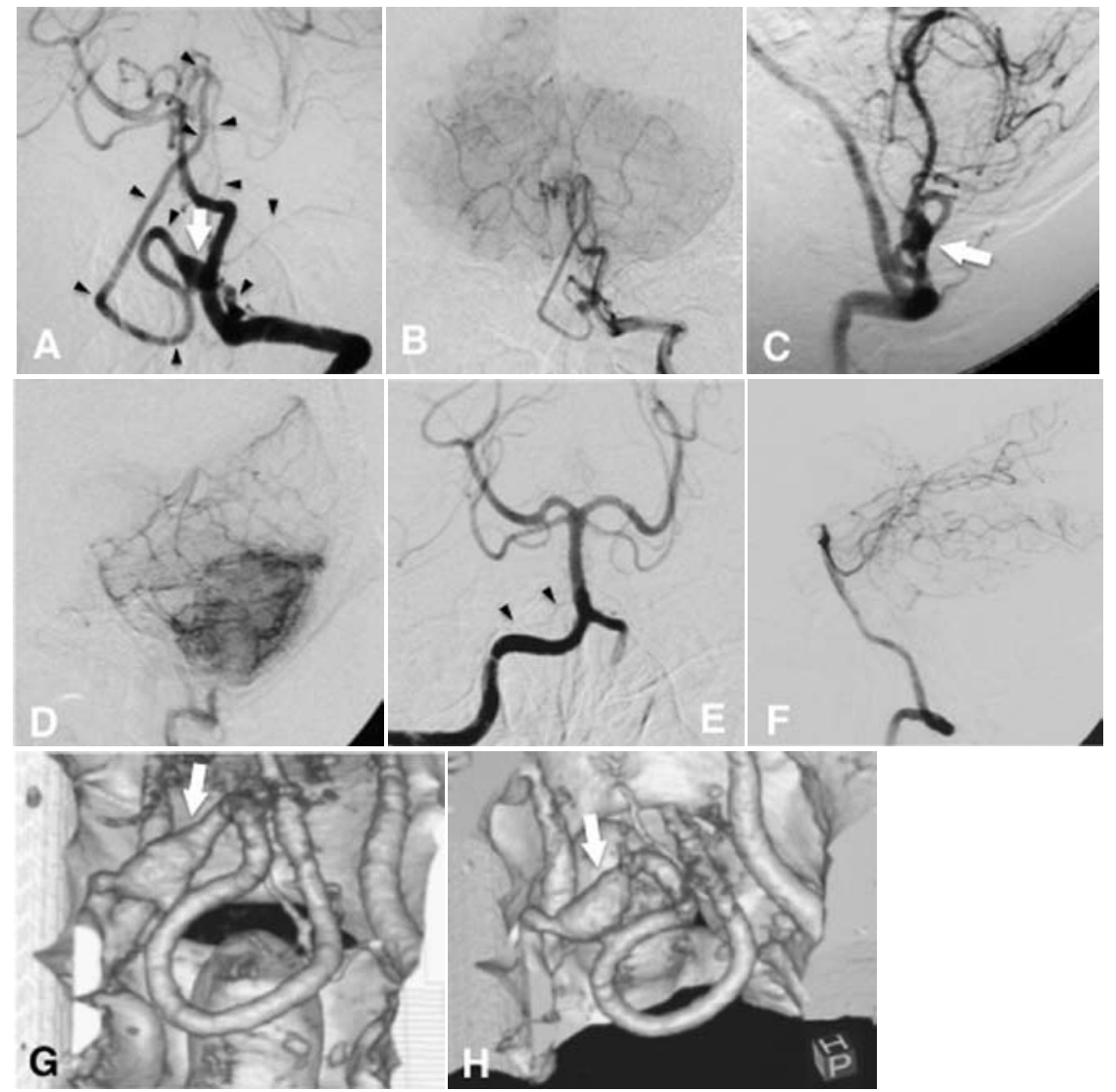

Fig. 2 Vertebral arteriography (VAG) on Day 2 (A-D: left, E, F: right, G, H: 3-D left). (A, B) Anteroposterior views of left VAG showing a dilated left PICA (black arrowheads) and a fusiform aneurysm (white arrow).

(C, D, G, H) Lateral and Posteroanterior views of left VAG demonstrating left PICA widely perfused posterior fossa and its aneurysm (white arrow).

(E) Anteroposterior view of right VAG showing hypoplasty of right AICA (black arrowheads) and absence of left AICA and right PICA.

(F) Lateral view of right VAG indicating avascular area of caudal part of posterior fossa without left PICA.

成や久損などのほか, 交通動脈(PICA communicating artery)などまれなものも存在する ${ }^{1113) 2122236)}$. Tokimura らは, PICA に限局する動脈㢚には, なんらかの後頭蓋窩 の血管破格 (vascular variation) が高率に合併し(28 例中 20 例, そのうち解離性動脈瘤には 3 例中 2 例 $)^{35)}$, 対側 PICA または同側 AICA 欠損が最も多く, 両枝欠損は囊状 瘤 2 例に認めた，と報告している，本例においては，左 PICA は大きく発達拡張し, 後頭蓋窩尾側の大部分を灌流 する一方, 左 AICA と右 PICA は確認できず, 右 AICA は低形成であった，対側の AICA 低形成も伴っているも のは，きわめてまれと考えられる，本例では病変部の病理 組織は得られなかったが，術中所見では明らかに紡錘状を 呈しており，解離性動脈瘤と推察された。本症例における 解離形成における正確な成因は明らかでないが，少なくと
も，著明に発達した左 PICA と他の PICA，AICA の低形 成から，血管形成異常に由来する脆弱性や，高い血管床血 管径比による血行力学的ストレスの関与は示唆される。画 像診断や情報処理技術の向上は近年特に著しく，とりわけ 脳動脈瘤や頚動脈狭窄症については, 数值流体解析 (computational fluid dynamics: CFD)が進み, streamline の作 成と wall shear stress (WSS), oscillatory shear index (OCI), energy loss (EL)の解析が可能となってきてい る ${ }^{45)(31) 32)}$ ，本例のような症例においては，今後， CFD の 応用による発生要因の解明が期待される.

本邦では, 頭蓋内動脈解離は椎骨脳底動脈系に多く, 出 血例における再出血は生命予後に特に大きく影響する ${ }^{23)}$ 28)。また，再出血までの期間は短く，治療のタイミングは とりわけ迅速である必要がある ${ }^{33)}$. 本例では, SAH 発症 


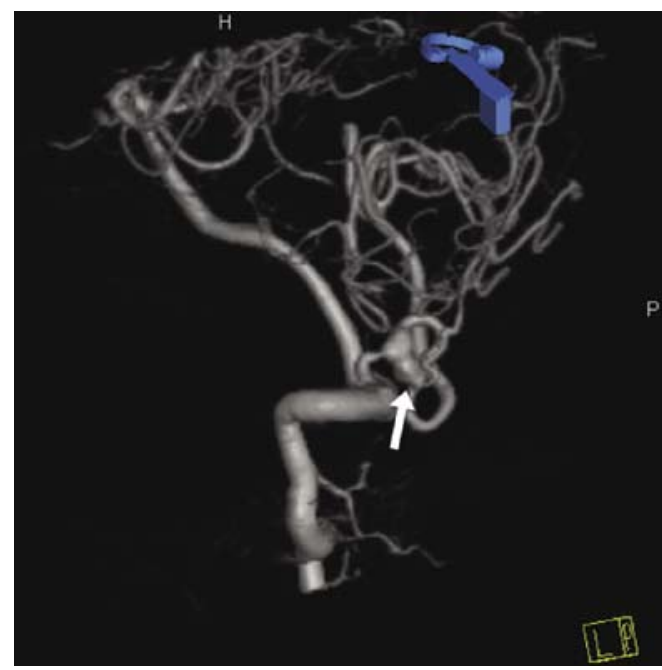

Fig. 3 Lateral view of the 2nd preoperative left VAG on the day 8 revealing the pseudo aneurysm of the fusiform aneurysm of left PICA (white arrow).

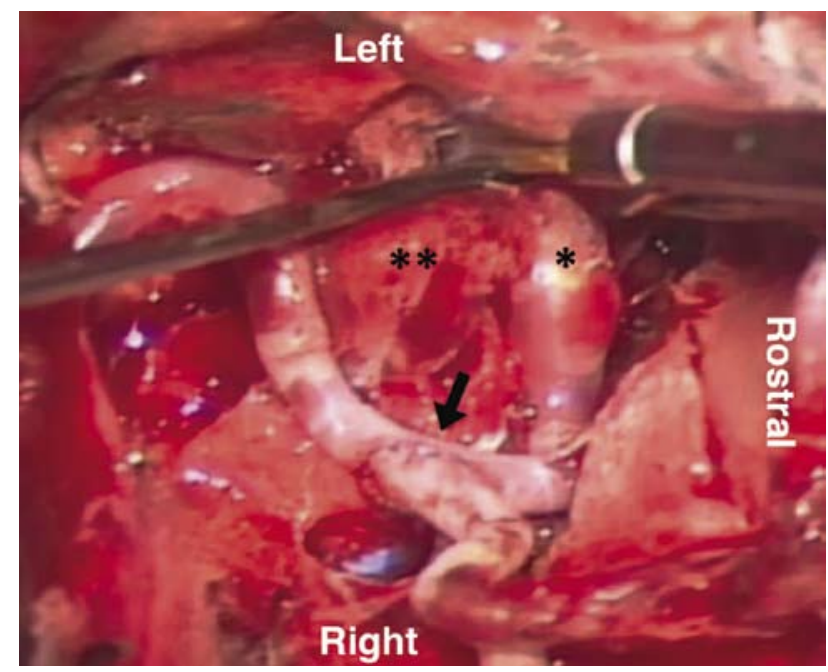

Fig. 4 Operative view showing the dissecting aneurysm $\left.{ }^{*}\right)$ with clot $\left({ }^{*}\right)$ and OA-PICA anastomosis (black arrow), which was successfully placed at just distal of the aneurysm.

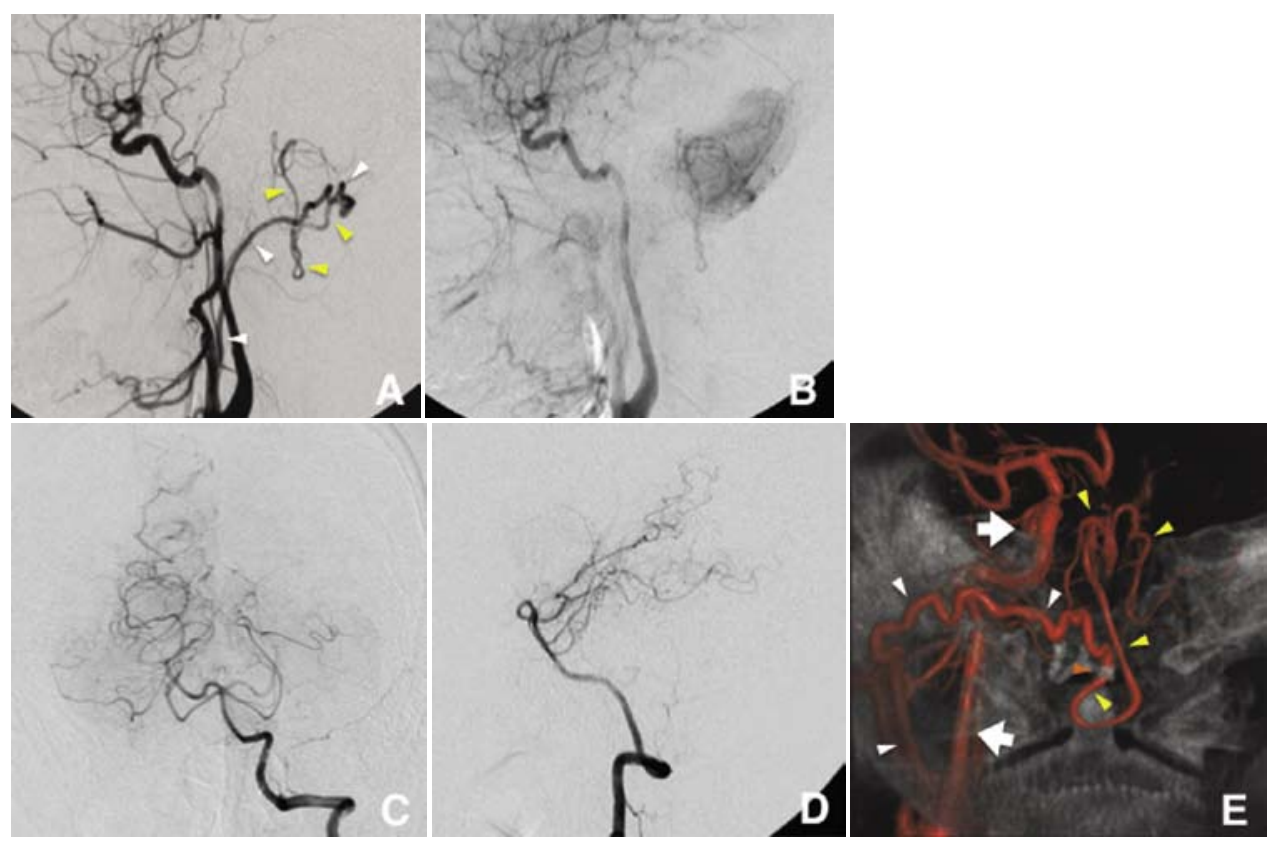

Fig. 5 Postoperative angiography on Day 25.

(A, B) Lateral views of left common carotid arteriography (CCAG) showing the patency of OA (white arrowheads) and PICA (yellow arrowheads).

Anteroposterior (C) and lateral (D) views of left VAG demonstrating that the aneurysm of left PICA was occluded. (E) Three-dimensional left CCAG showing the overview of OA (white arrowheads), OA-PICA anastomosis point (orange arrowhead), PICA (yellow arrowhead), and internal carotid artery (white arrow).

後, 第 6 病日に転送され, 脳血管攣縮が懸念されたが, 脳 血管攣縮が少ないとされる後方循環病変であったこと，そ の後の脳血管撮影で紡鍾状動脈瘤上に切迫破裂を示唆する 囊状隆起所見の増大がみられたことから, 再出血予防治療
が優先されると判断し第 11 病日に直達術による治療を 行った ${ }^{12) 17) .}$

頭蓋内解離性動脈瘤の治療に関しては, 内科的治療は, 急性期を脱した例の転帰は比較的良好であったとする報告 
もあるが27)，再出血した際には mortality が高く，外科治 療が第一選択と考えられている. 後頭蓋窩に発生した解離 性動脈瘤においては, 近年血管内治療の術者技術とデバイ スの進歩に伴い，親血管動脈瘤閉塞で良好な成績を得られ たとする報告が多(208)1520030)38). Cellern らは親血管閉塞 を行わない血管内治療も可能であり有用としているが，そ の長期成績や, 直達術に対する優位性, 劣性はいまだ不明 である ${ }^{633)}$ ，直達術は，解離瘤の特性上, 多くは clipping 困難であり, wrapping や trapping, proximal occlusion での治療となることもまれではない(10)1819)．PICA に限局 した動脈瘤においては, 後頭蓋窩の解離性動脈瘤の治療と 同様，血管内治療を推奨する報告が多いが，一方で種々の 合併症や治療後の再発率が高いことが報告されている37799) 24)。直達術は, 直視下での確実な再破裂予防が可能である ことに加えて, 外減圧や脳室ドレナージを迅速に同時施行 でき，水頭症をきたす可能性の高い同部破裂症例の脳圧管 理の点で有利といえる2535). 一方で動脈瘤の部位や形状, 脳幹への穿通枝の存在により, 機能温存の観点上 clipping のみならず trapping も困難な場合があることを銘記して おく必要がある ${ }^{14)}$. 解離性 PICA 動脈瘤に限定した治療報 告は少ないが, 後頭蓋窩に生じた他の解離性動脈瘤と同 様, 高率に出血・再出血をきたし, 予後不良と報告され, 前述の治療に準じて行われることが多( ${ }^{8141416) 33)}$. 本症例 では, 動脈瘤の形状や, 親血管の灌流域とその機能解剖的 観点から, 血管内治療での確実な再破裂予防と親血管温存 再立は困難と判断した. また, 比較的若年であることから， 確実な血行再建が必須であると判断して直達術 (trapping + bypass）を選択し，良好な長期成績を得られた ${ }^{1)}$.

\section{結語}

後下小脳動脈に発生した解離性動脈瘤の出血例を経験し た，同部位の解離例はきわめてまれであり，著明に発達し た左 PICA と他の PICA, AICA の低形成による血行力学 的ストレスが出血性動脈解離の発生に起因したものと推察 された，後方循環系の出血性動脈解離に対する治療は，血 管内治療が一定の成果をあげているが，直達術による血行 再建の必要性が高い症例も一部存在することを銘記し， 個々の症例に応じた治療戦略を構築する必要がある。

\section{文献}

1) Ali MJ, Bendok BR, Tawk RG, et al: Trapping and revascularization for a dissecting aneurysm of the proximal posteroinferior cerebellar artery: technical case report and review of the literature. Neurosurgery 51: 258-262; discussion 262-253, 2002

2) Anxionnat R, de Melo Neto JF, Bracard S, et al: Treatment of hemorrhagic intracranial dissections. Neurosurgery 53: 289-300; discussion 300-281, 2003
3) Bradac GB, Bergui M: Endovascular treatment of the posterior inferior cerebellar artery aneurysms. Neuroradiology 46: 1006-1011, 2004

4) Cebral JR, Mut F, Weir J, et al: Quantitative characterization of the hemodynamic environment in ruptured and unruptured brain aneurysms. AJNR Am J Neuroradiol 32: 145-151, 2011

5) Cebral JR, Castro MA, Burgess JE, et al: Characterization of cerebral aneurysms for assessing risk of rupture by using patient-specific computational hemodynamics models. AJNR Am J Neuroradiol 26: 2550-2559, 2005

6) Cellerini $\mathrm{M}$, Mangiafico $\mathrm{S}$, Ammannati $\mathrm{F}$, et al: Ruptured, dissecting posterior inferior cerebellar artery aneurysms: endovascular treatment without parent vessel occlusion. Neuroradiology 50: 315-320, 2008

7) Chalouhi N, Jabbour P, Starke RM, et al: Endovascular treatment of proximal and distal posterior inferior cerebellar artery aneurysms. J Neurosurg 118: 991-999, 2013

8) Dinichert A, Rüfenacht DA, Tribolet N: Dissecting aneurysms of the posterior inferior cerebellar artery: report of four cases and review of the literature. J Clin Neurosci 7: 515-520, 2000

9) Fujimura M, Nishijima M, Midorikawa $H$, et al: Fatal rupture following intra-aneurysmal embolization for the distal posterior inferior cerebellar artery aneurysm with parent artery preservation. Clin Neurol Neurosurg 105: $117-120,2003$

10) Fujitsu K, Ishiwata $Y$, Gondo G, et al: Wrap-clipping with a Dacron mesh silastic sheet. Technical note. $J$ Neurosurg 80: 336-337, 1994

11）藤原和則, 鹳藤 順, 金山重明：PICA Communicating Arteryに発生した多発性動脈瘤の 1 例. 脳神経外科 27 : 177-182, 1999

12) Hirashima $\mathrm{Y}$, Kurimoto $\mathrm{M}$, Hori $\mathrm{E}$, et al: Lower incidence of symptomatic vasospasm after subarachnoid hemorrhage owing to ruptured vertebrobasilar aneurysms. Neurosurgery 57: 1110-1116; discussion 1110-1116, 2005

13) Hlavin ML, Takaoka Y, Smith AS: A "PICA communicating artery" aneurysm: case report. Neurosurgery 29: 926-929, 1991

14) Hudgins RJ, Day AL, Quisling RG, et al: Aneurysms of the posterior inferior cerebellar artery. A clinical and anatomical analysis. J Neurosurg 58: 381-387, 1983

15) Iihara K, Sakai N, Murao K, et al: Dissecting aneurysms of the vertebral artery: a management strategy. $J \mathrm{Neu}$ rosurg 97: 259-267, 2002

16) Ishikawa $T$, Suzuki A, Yasui N: Distal posterior inferior cerebellar aneurysms--report of 12 cases. Neurol Med Chir (Tokyo) 30: 100-108, 1990

17) Kang MS, Kim JH, Kang HI, et al: Risk factors affecting clinical outcome of ruptured vertebrobasilar saccular aneurysms. J Cerebrovasc Endovasc Neurosurg 14: 175180, 2012

18) Kawamata $T$, Tanikawa $T$, Takeshita $M$, et al: Rebleeding of intracranial dissecting aneurysm in the vertebral artery following proximal clipping. Neurol Res 16: 141144, 1994

19) Kitanaka C, Morimoto $\mathrm{T}$, Sasaki $\mathrm{T}$, et al: Rebleeding from vertebral artery dissection after proximal clipping. Case report. J Neurosurg 77: 466-468, 1992

20) Lim SM, Choi IS, Hum BA, et al: Dissecting aneurysms 
of the distal segment of the posterior inferior cerebellar arteries: clinical presentation and management. AJNR Am J Neuroradiol 31: 1118-1122, 2010

21) Lister JR, Rhoton AL Jr, Matsushima T, et al: Microsurgical anatomy of the posterior inferior cerebellar artery. Neurosurgery 10: 170-199, 1982

22) Mazighi M, Porter PJ, Rodesch G, et al: Vascular anomalies and the risk of multiple aneurysms development and bleeding. Interv Neuroradiol 8: 15-20, 2002

23）水谷 徹, 有賀 徹: クモ膜下出血で発症した椎骨脳底動 脈解離性動脈瘤における再出血の時期, 頻度と転帰 自験 20 例および文献 48 例の検討. 脳卒中の外科 22: 389-393, 1994

24) Mukonoweshuro W, Laitt RD, Hughes DG: Endovascular treatment of PICA aneurysms. Neuroradiology 45: 188192, 2003

25) Nussbaum ES, Madison MT, Goddard JK, et al: Peripheral intracranial aneurysms: management challenges in 60 consecutive cases. J Neurosurg 110: 7-13, 2009

26）大石博通, 古口徳雄, 小林繁樹, ほか: 【出血発症の PICA involved dissection aneurysm】出血発症の PICA involving dissecting aneurysmの治療一順行性血行を生かした近 位部母血管閉塞術一. 脳卒中の外科 33: 155-159, 2005

27）小野純一, 樋口佳則, 町田利生, ほか：〈も膜下出血で発 症した椎骨脳底動脈系の頭蓋内解離性動脈病変の検討一病 態㧍よび外科的治療成績一. 脳卒中の外科 35: 124-129, 2007

28）小野純一, 平井伸治, 芹澤 徹, ほか：椎骨脳底動脈系解 離性動脈病変の転帰決定因子 再出血に影響を及ぼす因子 の検討．脳神経外科ジャーナル 11: 265-270, 2002

29) Pasqualin A, Da Pian R, Scienza R, et al: Posterior inferior cerebellar artery aneurysm in the fourth ventricle: acute surgical treatment. Surg Neurol 16: 448-451, 1981

30) Sedat J, Chau Y, Mahagne MH, et al: Dissection of the posteroinferior cerebellar artery: clinical characteristics and long-term follow-up in five cases. Cerebrovasc Dis 24: 183-190, 2007

31) Shojima M, Oshima M, Takagi K, et al: Magnitude and role of wall shear stress on cerebral aneurysm: computational fluid dynamic study of 20 middle cerebral artery aneurysms. Stroke 35: 2500-2505, 2004

32）高尾洋之, 山本 誠, 大塚 忍, ほか：【脳動脈瘤に対する 新たな考え方】数值流体力学 $(\mathrm{CFD})$ を用いた脳動脈瘤解析. 脳神経外科ジャーナル 21: 298-305, 2012

33) Tawk RG, Bendok BR, Qureshi AI, et al: Isolated dissections and dissecting aneurysms of the posterior inferior cerebellar artery: topic and literature review. $\mathrm{Neu}$ rosurg Rev 26: 180-187, 2003

34) Teitelbaum GP, Dowd CF, Larsen DW, et al: Endovascular management of biopsy-related posterior inferior cerebellar artery pseudoaneurysm. Surg Neurol 43: 357359, 1995

35) Tokimura H, Yamahata H, Kamezawa $T$, et al: Clinical presentation and treatment of distal posterior inferior cerebellar artery aneurysms. Neurosurg Rev 34: 57-67, 2011

36）鵜殿弘貴, 白石哲也, 辻 武寿, ほか：真の “PICA communicating artery” aneurysm の 1 例. 脳神経外科 25: 763766, 1997

37) Yamakawa H, Kaku Y, Yoshimura S, et al: Two cases of dissecting aneurysm of the distal posterior inferior cerebellar artery: possible involvement of segmental mediolytic arteriopathy in the pathogenesis. Clin Neurol Neurosurg 107: 117-122, 2005

38) Yamaura I, Tani E, Yokota M, et al: Endovascular treatment of ruptured dissecting aneurysms aimed at occlusion of the dissected site by using Guglielmi detachable coils. J Neurosurg 90: 853-856, 1999 